\title{
Gestão Integrada de Águas Pluviais em Conjunto Habitacional Multifamiliar: Experimento Casa Nordeste 1.0
}

\author{
ROCHA, Carlos Adilson Alves ${ }^{1}$ \\ LEITE, Bruno José de Macedo Silva² \\ MANGUEIRA, Filipe Gonzales Nobre ${ }^{3}$ \\ GAMA, Vivian Rodrigues ${ }^{4}$ \\ NOME, Carlos Alejandro 5
}

${ }^{1}$ Laboratório de Modelos mais Prototipagem, Universidade Federal da Paraíba, João Pessoa, Brasil. carlos.adilsonpb@hotmail.com. 2Laboratório de Modelos mais Prototipagem, Universidade Federal da Paraíba, João Pessoa, Brasil. brunomac97@gmail.com.

${ }^{3}$ Laboratório de Modelos mais Prototipagem, Universidade Federal da Paraíba, João Pessoa, Brasil. fgonzales.arq@gmail.com

${ }^{4}$ Laboratório de Modelos mais Prototipagem, Universidade Federal da Paraíba, João Pessoa, Brasil. viviangama_@hotmail.com.

5Laboratório de Modelos mais Prototipagem, Universidade Federal da Paraíba, João Pessoa, Brasil. carlos.nome@gmail.com.

\begin{abstract}
Resumo
A crescente demanda por água nos grandes centros urbanos vem ocasionando situações de estresse hídrico nas redes conectadas a eles. Nesse cenário, a água pluvial se mostra uma fonte alternativa válida para suprir as necessidades deste bem. Entretanto, as alternativas vêm se mostrando de difícil implementação, levando-se em consideração o adensamento vertical atual. Dito isso, este trabalho teve como objetivo analisar, a nível projetual, a viabilidade operacional, social e econômica de um modelo de gestão integrada de reuso de águas pluviais no contexto de conjunto de habitação multifamiliar evolutivo, composto por tecnologias desenvolvidas previamente por pesquisadores e aplicadas no experimento CASA NORDESTE 1.0. Como resultado, o sistema integrado permite a otimização das tecnologias, em harmonia com a estrutura do edifício, com uma economia de $R \$ 163,00$ reais mensais, considerando um volume aproveitável de $42,6 \mathrm{~m}^{3} / \mathrm{mês}$, reduzindo demandas locais econômicas, de alocação e energéticas. Por fim, o projeto apresenta potencial de viabilidade em metrópoles com problemas de adensamento populacional, drenagem urbana e estresse hídrico, além de apresentar uma dinâmica evolutiva podendo ser expandido ou suprimido de acordo com a demanda.
\end{abstract}

Palavras-Chave: gestão integrada; águas pluviais; habitação multifamiliar.

\begin{abstract}
The increasing demand for water supply in large urban centers is destabilizing the hydric network connected to them. In this scenario, rainwater shows itself as a valid alternative source to supply the needs of this good. However, these alternative systems are proving difficult to implement, considering the current vertical density. The objective of this work was to analyze at a projectual level the operational, social and economic viability of an integrated rainwater reuse management model in the context of an evolving multifamily housing complex, composed of technologies previously developed by researchers and applied in the experiment CASA NORDESTE 1.0. As a result, the integrated system allows the optimization of the technologies in harmony with the building structure, saving of $R \$ 163.00$ per month, considering a usable volume of $42,6 \mathrm{~m}^{3} / \mathrm{month}$, then reducing local economic demands, allocation and energy. Finally, the project presents the potential viability in metropolis with problems of population density, urban drainage and water stress, besides presenting an evolutionary dynamics that can be expanded or suppressed according to the demand.
\end{abstract}

Key-Words: integrated management; rain water; multifamily housing. 


\section{Introdução}

A ausência de consenso global acerca do uso racional de fontes alternativas de água acentua a indisponibilidade deste recurso, devido ao seu uso insustentável nos mais variados setores. Em regiões de insegurança hídrica, essa situação se mostra ainda mais grave. Nesse sentido, o debate referente a escassez de água envolve, além de questões éticas, culturais e sociais, também problemas relacionados a má gestão pública do recurso.

A aplicação da ciência, tecnologia e inovação à gestão de recursos hídricos disponíveis é essencial para aumentar a eficiência do seu uso. Assim, através da otimização das tecnologias de inovação frente a gestão de recursos hídricos é possível adequar o balanço entre disponibilidade e demanda de suprimento de água, garantindo a maximização da relação entre benefícios e custos, e a minimização dos impactos ambientais (INSA, 2011).

Nesse contexto, sistemas integrados de captação e reuso de águas pluviais apresentam-se como alternativas socioambientais para demandas individuais e coletivas, podendo suprir necessidades primárias e secundárias. As tecnologias de armazenamento e captação de águas da chuva podem ser utilizadas como estratégia de controle de cheias, através da diminuição da quantidade de água escoada para o sistema de drenagem, além de servirem como fonte alternativa para suprimento em edificações residenciais (PETERS, 2006; GHISI e FERREIRA, 2007; MALQUI, 2008), comerciais (SILVA, 2007) e industriais (VALLE et al., 2007).

\section{O Projeto Habitacional}

O projeto de habitação multifamiliar desenvolvido pela equipe da CASA NORDESTE 1.0 compreende duas escalas: a da unidade habitacional, e a do desenho urbano e agenciamento. Ambas as escalas seguem três conceitos básicos: 1- evolutividade e flexibilidade dos espaços; 2 - utilização de materiais e tecnologias construtivas sustentáveis, inovadoras, de baixo impacto ambiental e disponíveis na região Nordeste brasileira; 3 - utilização de sistemas de projeto open source.

O experimento habitacional proposto pela equipe CASA NORDESTE 1.0 é desenvolvido com base no local da competição, que será realizada na cidade de Cali, na Colômbia (embora a lógica do projeto seja com que ele seja passível de ser implantado em diversas localidades). É formado por uma área de telhado de $544 \mathrm{~m}^{2}$ e consumo não nobre relacionado a usos externos na Tabela 1.

Tabela 1: Relação de consumo de uso externo predial.

\begin{tabular}{lll}
\hline Uso Externo & Unidade & Valor \\
\hline Gramado ou Jardim & Litros/dia/m² & 2 \\
Lavagem de carros & Litros/lavagem/carro & 150 \\
Mangueira de jardim 1/2” x 20m & Litros/dia & 50 \\
Limpeza de pátios comuns & Litros $/ \mathrm{m}^{2} / \mathrm{dia}$ & 2 \\
\hline \multicolumn{2}{c}{ Fonte: TOMAZ (2003) }
\end{tabular}

Sendo assim, o volume de água demandada para fins não nobres, num conjunto habitacional vertical composto por sete blocos semelhantes à unidade original, gira em torno de $1.400 \mathrm{~L} / \mathrm{dia}$. Busca-se, assim, responder as diferentes demandas dos seus possíveis usuários e aos diferentes contextos onde o projeto venha a ser implantado. Os conceitos mencionados se moldam a diferentes cenários urbanos; e se desenrolam nas soluções esclarecidas a seguir.

O estudo de caso é uma edificação de oito pavimentos, cuja estrutura metálica determina a modulação das unidades habitacionais. A planta-tipo prevê duas unidades habitacionais por andar além da caixa de circulação vertical e da circulação horizontal. Favorece assim a exaustão das edificações, além da passagem de equipamentos hidráulicos, dois fossos são implantados entre a unidade e a circulação 
vertical. A coberta possui um único caimento e direciona as águas para uma calha única ao longo de toda sua extensão.

O agenciamento da edificação se adapta à topografia existente. Ela prevê áreas verdes ao redor da edificação, como mostra a Figura 1. Em sua face frontal estão distribuídas hortas e biovaletas.

Figura 1: Esquema da edificação.

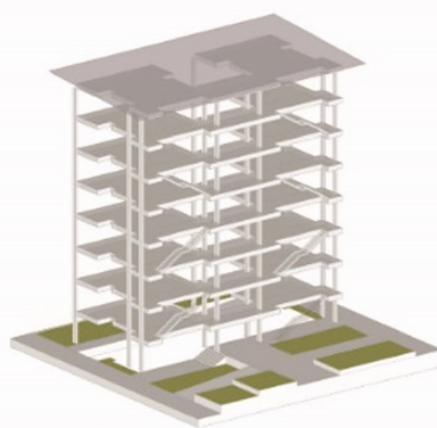

SISTEMA ESTRUTURAL E COBERTA

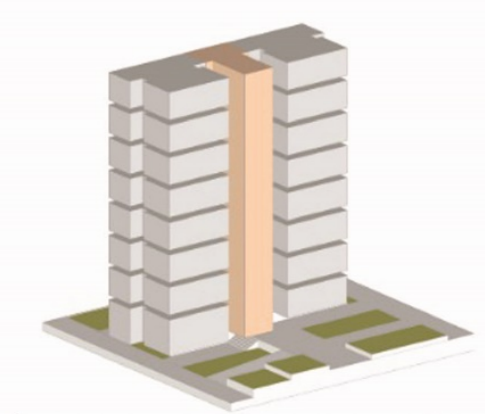

MÓDULOS DAS UNIDADES HABITACIONAIS E CIRC. VERTICAL

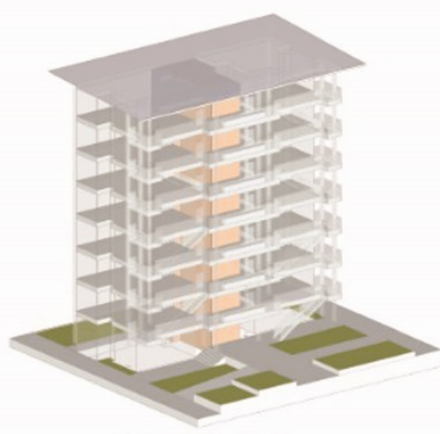

EDIFICAÇÃO COMPLETA

Fonte: Autores.

\section{Sistemas de Gestão Integrada}

O sistema de gestão integrada formulado pelo seguinte trabalho é composto por tecnologias desenvolvidas previamente por pesquisadores e aplicadas no protótipo CASA NORDESTE 1.0. O protótipo é atualmente desenvolvido pela equipe do Laboratório de Modelos e Prototipagem $(L M+P)$ do Departamento de Arquitetura e Urbanismo da Universidade Federal da Paraíba, em resposta à competição internacional de estudantes organizada pelo Departamento de Energia dos Estados Unidos em conjunto com o governo Colombiano, Solar Decathlon 2019, versão Latin America \& Caribbean.

\subsection{Sistema de Captação e Armazenamento}

O sistema de captação e armazenamento de águas pluviais proposto no protótipo CASA NORDESTE 1.0, consiste numa Minicisterna com papel de filtrar o volume de chuva. O sistema é alocado diretamente na saída da calha coletora do telhado, onde ocorre o recolhimento e direcionamento do fluxo precipitado, sendo composto por (Figura 2, 3 e 4):

- um filtro autolimpante de sólidos grosseiros, localizado após a saída da calha;

- um separador de águas para levar a descarte a primeira chuva;

- uma minicisterna para armazenar o volume aproveitável;

- um extravasor hidráulico para eliminar, se necessário, o volume excedente e impedir a entrada de insetos através de uma tela de proteção.

Figura 2: Filtro autolimpante

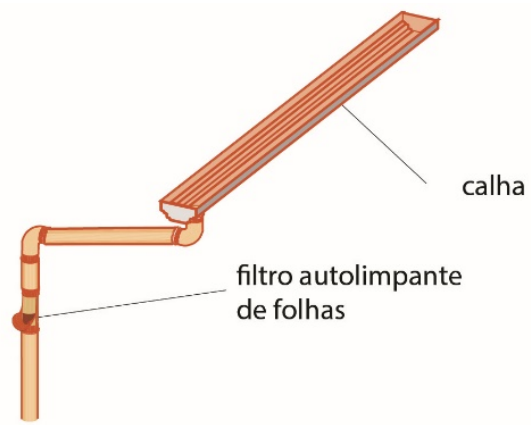

Fonte: autores
Figura 3: Sistema de captação e armazenamento

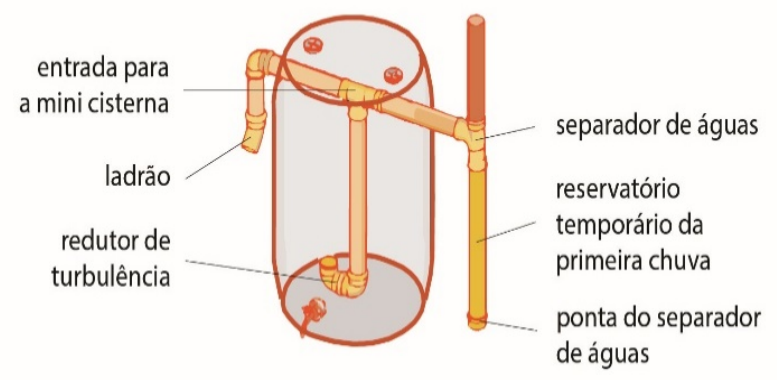

Fonte: autores 
Figura 4: Sistema de captação e armazenamento implementado na edificação

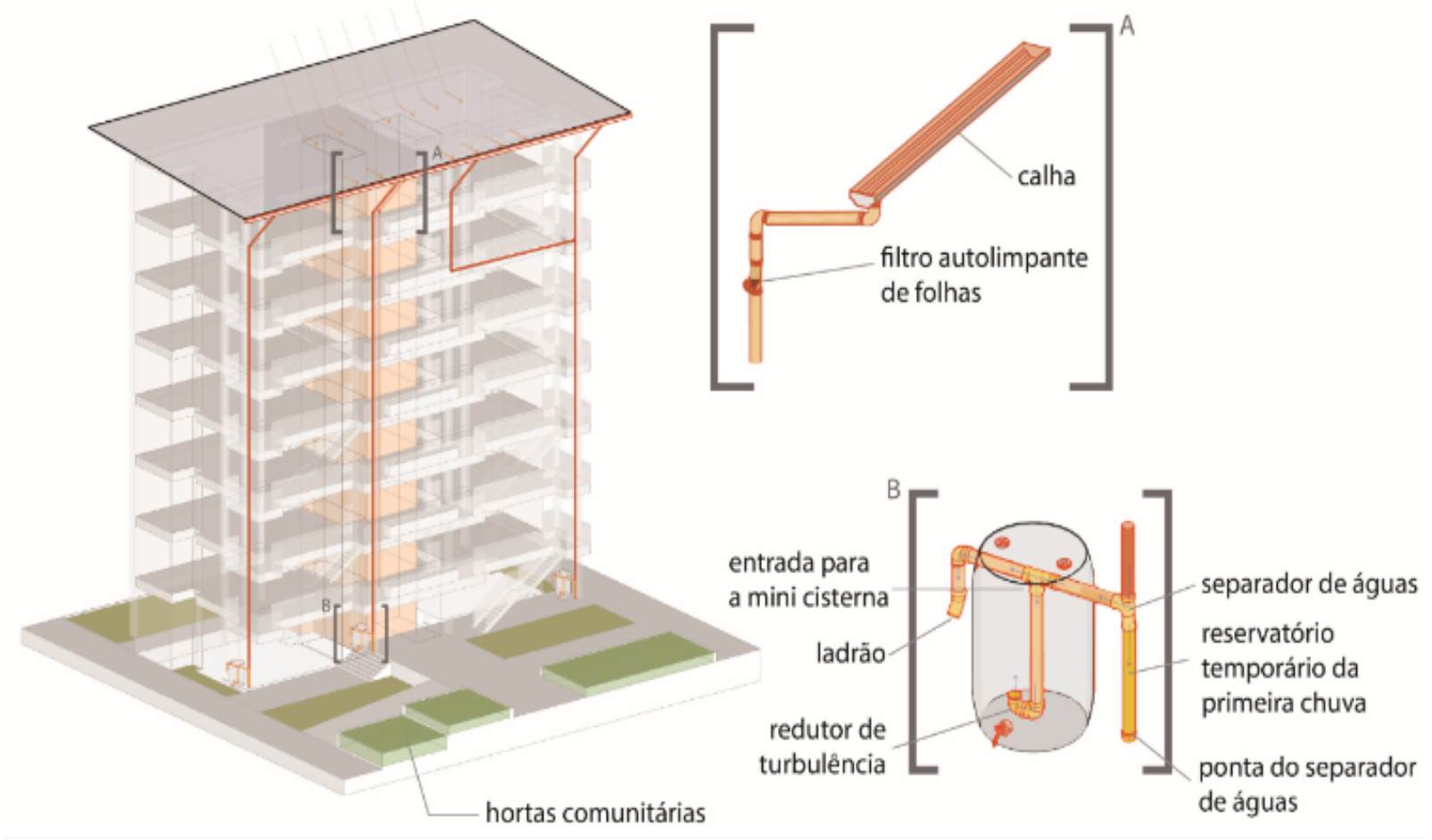

Fonte: autores

Para seu dimensionamento, são necessários cálculos da área de contribuição do telhado edificação, além da quantidade aproveitável e de descarte do primeiro volume precipitado. Entretanto, para fins de irrigação, todo o volume coletado pode ser reutilizado.

Para efeito de cálculo, o volume de água de chuva que pode ser aproveitado não é o mesmo que o precipitado. Para isto, usa-se um coeficiente de escoamento superficial, ou coeficiente de Runoff, que é o coeficiente entre a água que escoa superficialmente, pelo total da água precipitada (TOMAZ, 2003).

O volume aproveitável é determinado através da Equação 1:

$V=P \times A \times C \times \eta$

Onde:

$V=$ Volume anual, mensal ou diário aproveitável (L).

$P=$ Precipitação média anual, mensal ou diária $(\mathrm{mm})$.

$A=$ Área de coleta $\left(\mathrm{m}^{2}\right)$.

$C=$ Coeficiente de Runoff (normalmente 0,95).

$\eta=$ Fator de captação (eficiência do sistema de captação).

De acordo com os dados obtidos, a precipitação média de João Pessoa é 3,05 mm/dia (AESA, 2018), sendo então o volume a ser aproveitado dado a partir do coeficiente de Runoff citado anteriormente, bem como da eficiência do sistema de descarte, adotando-se a Equação 1.

Valores de eficiência de captação do sistema variam de 0,50 a 0,90. Um valor prático recomendado sem considerar o volume de descarte, é $\eta=0,9$. 
Sendo assim, o volume diário aproveitado é de:

$V=3,05 \times 544 \times 0,95 \times 0,9=1.420 \mathrm{~L} / \mathrm{dia}$

Para o cálculo da vazão de projeto, que será utilizada para dimensionamento das calhas e condutos verticais, foi utilizada a Equação 2 disposta na NBR 10844 (ABNT 1989) de instalações prediais de águas pluviais:

$Q=\frac{A I}{60}$

Onde:

$Q=$ Vazão de projeto, $L /$ min.

$A=$ Área de contribuição, $m^{2}$.

$\mathrm{l}=$ Intensidade pluviométrica, $\mathrm{mm} / \mathrm{h}$.

Obteve-se uma área de contribuição de $563 \mathrm{~m}^{2}$ e utilizando uma intensidade pluviométrica de João Pessoa de $115 \mathrm{~mm} / \mathrm{h}$ (AESA, 2018), por possuir um regime pluviométrico semelhante a região colombiana onde será realizada a competição. A vazão de projeto de acordo com a Equação 2,é:

$Q=\frac{563 \times 155}{60}=1.080 \mathrm{~L} / \mathrm{min}$

De acordo com o cálculo acima, a calha será de $200 \mathrm{~mm}$ com 0,9\% de inclinação do tipo semicircular de PVC $(n=0,011)$ de acordo com a NBR 10844/1989, com condutores verticais serão de $100 \mathrm{~mm}$.

Esse sistema, com simples construção e manutenção, pode ser utilizado individualmente ou em conjuntos prediais. Além da redução de escoamento do volume de água no entorno da edificação, este modelo propicia abordagens para usos não nobres (irrigação de jardins, lavagens de pisos, carros, máquinas, descargas sanitárias, etc.) e usos nobres (preparação de alimentos, potabilidade direta, etc.), ocasionando consequente redução do consumo de água proveniente do abastecimento convencional.

Sua manutenção consiste na limpeza interna e externa do reservatório de armazenamento, além de se buscar alocações de fácil acesso e barrar a entrada de insetos e animais.

\subsection{Sistema de Irrigação}

Ao sistema de irrigação proposto no protótipo CASA NORDESTE 1.0 dá-se o nome de Acionador Simplificado para Irrigação (ASI) ou Pinga e foi desenvolvida, em 2010, pelos pesquisadores Leonardo Oliveira Médici e Daniel Fonseca de Carvalho, da Universidade Federal Rural do Rio de Janeiro e resume-se em um equipamento de regulação da quantidade de água na irrigação.

Consiste em uma vela de cerâmica de filtro de barro caseiro com função de sensor de umidade do solo onde este, quando está seco, cria um gradiente de pressão, puxando a água que está dentro de uma mangueira acoplada a vela e a um pressostato de máquina de lavar roupa. Após a água se deslocar em direção a vela, o pressostato aciona a válvula solenoide que libera a água para a irrigação. Quando o solo está suficientemente úmido, a vela, juntamente úmida, expulsa a água antes presente, reestabelecendo a pressão dentro da mangueira e desligando o pressostato, consequentemente, desligando a irrigação como mostrado na Figura 5 e 6. 
Figura 5: Sistema de irrigação

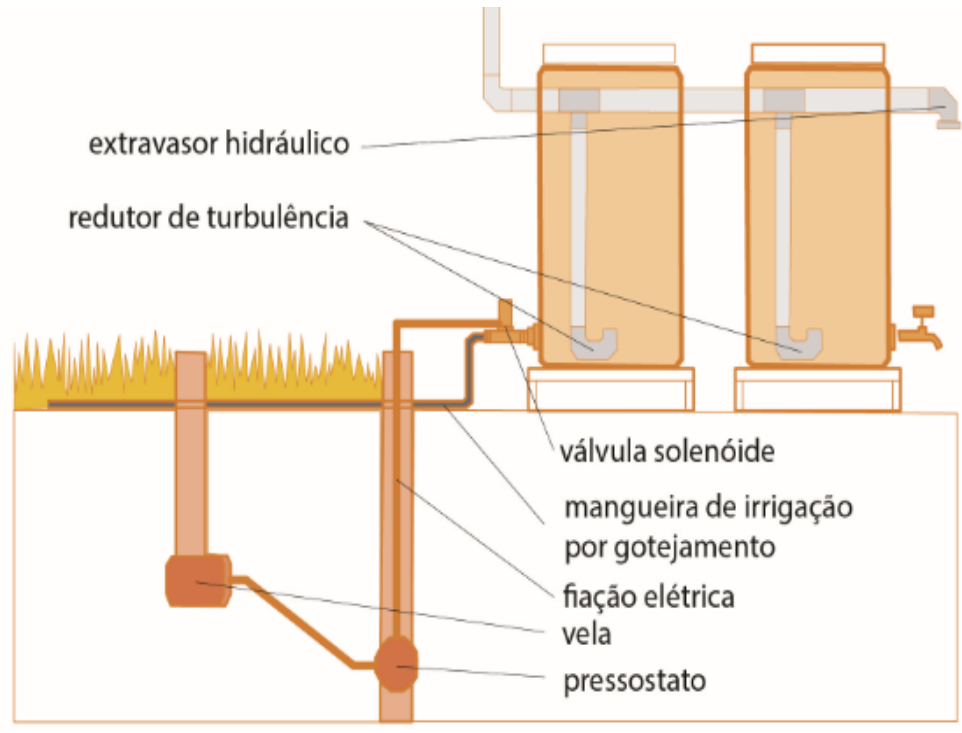

Fonte: autores

Figura 6: Sistema de irrigação instalado na edificação

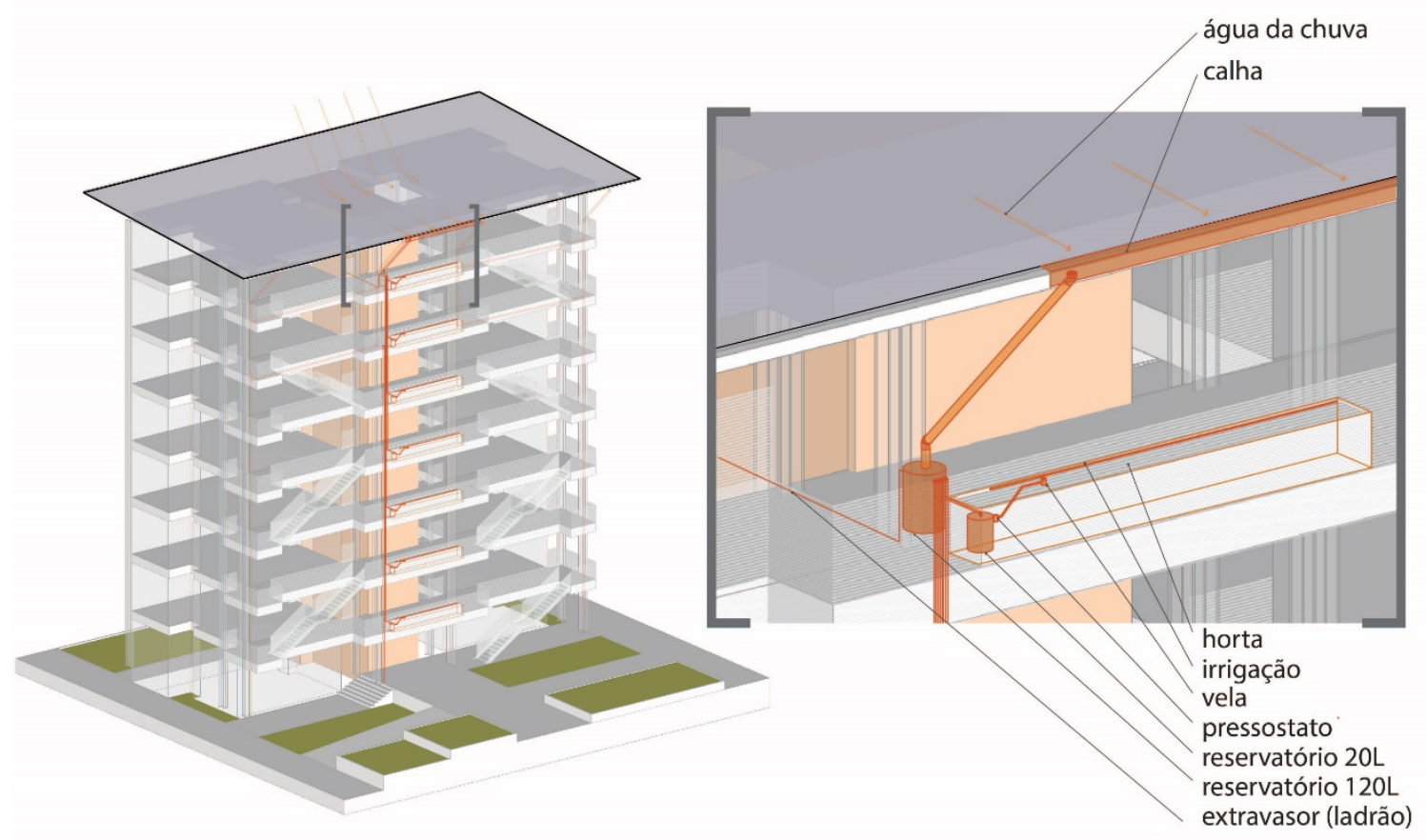

Fonte: autores

Este dispositivo garante a redução de gastos de água com irrigação, seja para jardins ou hortas, e apresenta baixo custo. Além disso, um único sistema pode irrigar até um hectare de área plana do mesmo solo, dependendo das condições do sistema de irrigação. Para casos de áreas menores, podese utilizar o modelo Nanopinga, desenvolvido pelos mesmos pesquisadores.

\subsection{Escoamento Superficial}

O sistema de escoamento superficial é pautado em partes no conceito da resiliência urbana, que, segundo Alberti et al. (2003), citado por Furtado, Priori e Alcântara (2015), pode ser medido pela forma 
com que uma cidade equilibra o ecossistema e as ações humanas. Desta forma, faz-se necessário garantir à cidade a capacidade de suportar os impactos gerados pela ocupação humana diante das demais contingências climáticas. Ao considerar a microescala local, optou-se pela implementação de biovaletas, ou valetas de biorretenção vegetadas, implantadas nos principais eixos do terreno urbanizado. Elas consistem em estratégias de infraestrutura verde, utilizadas como um processo auxiliador ao escoamento pluvial, que melhora a infiltração pluvial no solo, sua filtração (realizada tanto pela vegetação, quanto pelas camadas de solo), o aumento do tempo de vazão e a redistribuição do volume captado a possíveis sistemas de detenção de águas (PELLEGRINO e CORMIER, 2008). As biovaletas são alternativas a canteiros de escoamento superficial, normalmente utilizados em ruas ou estacionamentos. No entanto, nesta solução, o solo apresenta certa depressão conformativa, preenchido pela vegetação, e algumas camadas de solo filtrante (Figura 7).

Figura 7: Estrutura da biovaleta

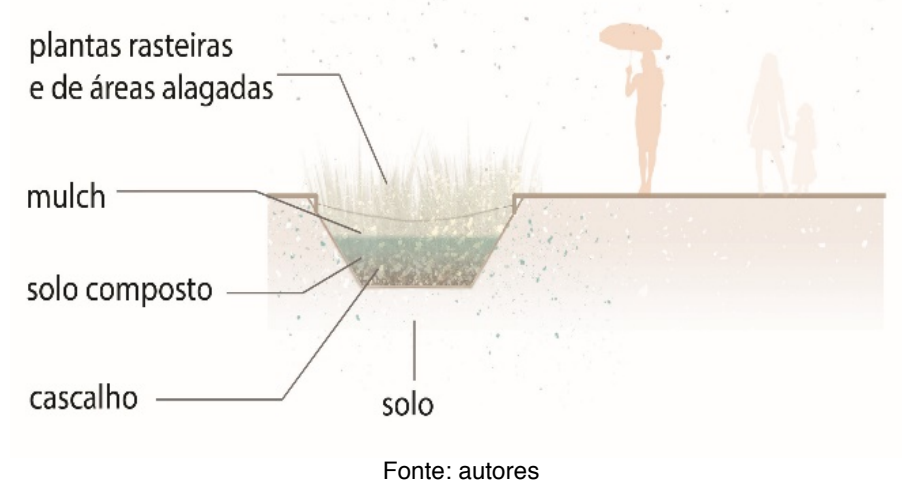

Além disso, no protótipo CASA NORDESTE 1.0, as valetas de biorretenção foram dispostas paralelamente ao principal eixo de circulação pedonal, situado em frente ao edifício, como demonstrado na Figura 8. Estes pontos que naturalmente apresentam um maior fluxo de circulação de pedestres, e desta forma uma maior carga acidental. Assim sendo, necessitam de uma maior eficácia quanto ao seu escoamento superficial, tanto em decorrência de sua característica urbana, quanto a necessidade de maior longevidade dos revestimentos adotados em piso.

Figura 8: Disposição das biovaletas.

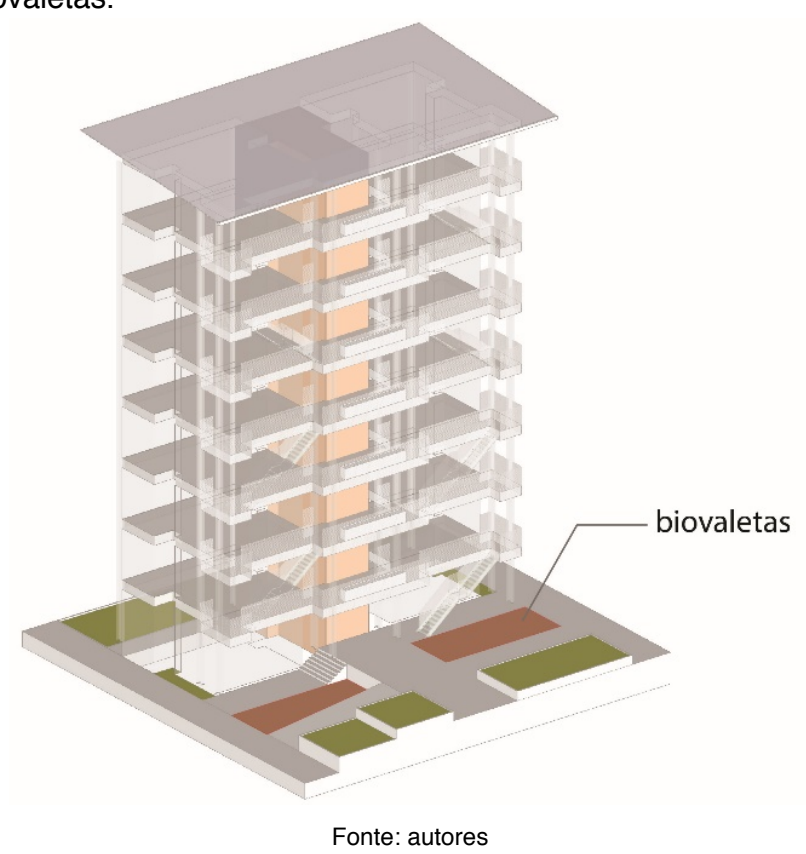


Neste sentido, o escoamento auxiliado pela utilização das biovaletas é justificado. Justificativa que é reforçada pela forma da solução adotada, uma vez que, sua configuração linear permite uma maior capacidade de captação do volume superficial, e colabora com o aumento do tempo de vazão das águas pluviais.

\section{Sistemas de Gestão Integrado}

O sistema integrado permite a otimização das técnicas apresentadas, aplicadas de forma a reduzir demandas locais econômicas, de alocação e energéticas. Ao atuar em conjunto, a proposta não requer uso de energia elétrica, não requer acionamento manual ou remoto e opera pelas características locais (temperatura, umidade, propriedades do solo ou substrato, etc.). A solução completa está disposta na Figura 9 a seguir.

Figura 9: Sistema integado.

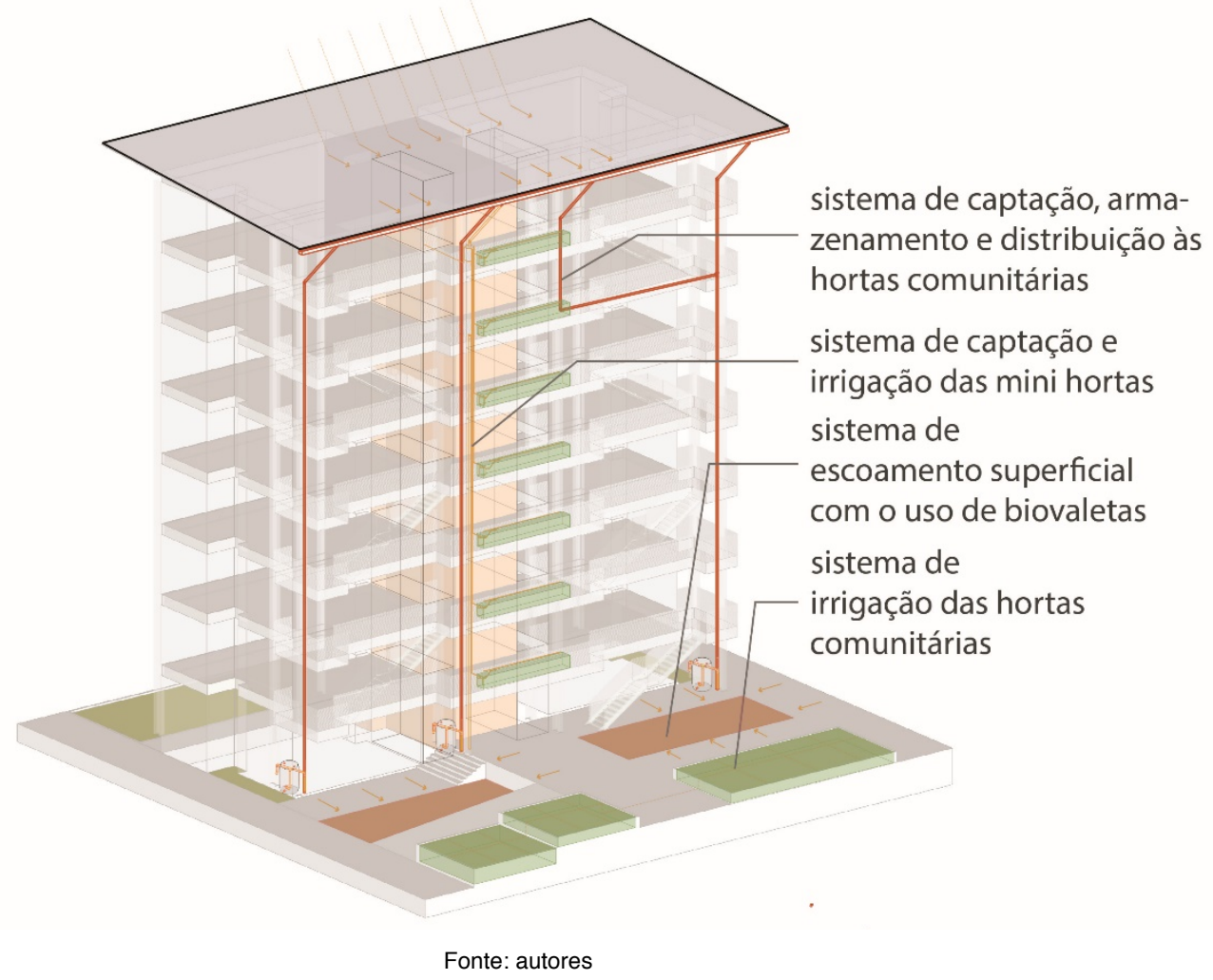

O sistema completo pode ser aplicado em unidades habitacionais residenciais e prediais com custo variado dependendo da finalidade de reuso. Os custos fixos de operação do sistema de irrigação estão dispostos na Tabela 2 abaixo.

Tabela 2: Orçamento do sistema de irrigação.

\begin{tabular}{ll}
\hline Peças & Preço (R\$) \\
\hline 1 Pressostato & 16,00 \\
1 Vela de filtro caseio & 6,00 \\
1 Mangueira (10m) & 15,00 \\
1 Válvula solenoide & 17,00 \\
TOTAL & $\mathbf{5 4 , 0 0}$ \\
\hline
\end{tabular}

Fonte: Autores, 2018. 
Sendo assim, o total de sete mini-hortas verticais e uma horta térrea soma $R \$ 378,00$ reais em equipamentos de irrigação. Já o sistema de captação formado por cinco mini-cisternas, soma um valor de $\mathrm{R} \$ 1.500,00$ reais, segundo o site SempreSustentável, desenvolvido pelo pesquisador Edson Urbano, levando em consideração sua utilização em série.Por fim, o custo total dos sistemas é de $R \$ 1.950,00$ reais, que, considerando ainda o pequeno gasto com instalação e manutenção, se mostra satisfatório. Além disso, de acordo com a Companhia de Água e Esgoto do Estado da Paraíba (CAGEPA), no ano de 2018, a tarifa mensal comum na cidade de João Pessoa é de $R \$ 3,79 / \mathrm{m} 3$, sendo então a utilização do sistema integrado responsável por uma economia de $R \$ 163,00$ reais mensais, considerando um volume aproveitável de $43 \mathrm{~m}^{3} / \mathrm{mês}$. Isto significa que há um potencial de em um retorno ao investimento de 12 meses.

\section{Considerações Finais}

A demanda por água e seu uso de maneira insustentável aumentam, cada vez mais, principalmente nas grandes cidades brasileiras. Mesmo o Brasil sendo um país com abundância de recursos hídricos, estes muitas vezes se encontram contaminados ou saturados por requerentes.

Com isto, se investe bastante em sistemas de tratamento e descontaminação de água, os quais são extremamente caros. Porém, não se busca fontes alternativas e mais sustentáveis de água, como é o caso das águas pluviais.

Este recurso é bastante cobiçado nas regiões mais áridas do Brasil, mas pouco observado pelos gestores públicos das cidades litorâneas as quais estas já estão passando por situações de estresse hídrico. Além disso, outro problema que se enfrenta, é a implementação de sistemas que capte a água de chuva em grandes centros urbanos onde a malha urbana é tão densa que os lotes ficam sem espaços para inserção de grandes reservatórios de armazenamento.

Diante deste cenário, as tecnologias apresentadas geram certa harmonia com o edifício vertical de média ou baixa altura, o qual é o modelo habitacional que mais cresce nas cidades tendo em vista a falta de espaço horizontal. Ademais, a alocação dos sistemas é simples e discreta de forma a otimizar o espaço do lote e captar o máximo de água pluvial possível.

Vale salientar, que ao implementar esses sistemas, principalmente o de biovaletas, a drenagem do edifício aumenta significativamente. Deste modo, há um benefício direto para a infraestrutura urbana ao expandir os tempos de pico, nas precipitações, com potencial redução de alagamentos. Este é um grande problema das cidades, visto que nos centros urbanos corre um aumento continuado das superfícies impermeabilizadas.

Contudo, mesmo que a nível esquemático o resultado tenha sido satisfatório no ponto de vista operacional, econômico e social, necessita-se da aplicação do trabalho em escala real para avaliação e confronto dos dados de campo com os dados de projeto. Aferição do sistema permitirá maturar o entendimento sobre a viabilidade econômica do mesmo. Esta viabilidade econômica permitirá que o sistema seja considerado como um gerador de renda mensal, a qual pode ser parcialmente reinvestida para o desenvolvimento de outras ações sustentáveis e parte em economia direta.

Considera-se que os modelos matemáticos e dados pluviométricos podem muitas vezes variar de região para região inviabilizando os sistemas análogos. Reconhecidamente é necessário desenvolvimento de estudos para obter resultados mais precisos no dimensionamento além de testar a eficiência de cada sistema em diferentes cenários.

Portanto, mesmo que em caráter experimental o protótipo CASA NORDESTE 1.0 apresenta soluções inovadoras reconhecendo que é fundamental a utilização e o correto manejo das águas pluviais. Tratase de um recurso muito interessante e uma grande alternativa para cidades em racionamento de água, com a implementação de sistemas simples, baratos e eficientes. 


\section{Agradecimentos}

Esta pesquisa foi desenvolvida com o auxílio do Laboratório de Modelos mais Prototipagem da Universidade Federal da Paraíba. Agradecemos a toda a equipe do experimento CASA NORDESTE 1.0, e com muito carinho a graduanda em Arquitetura e Urbanismo, da citada instituição, Alice Maria Nobrega Piva de Carvalho pelas contribuições prestadas, além do nosso orientador Dr. PhD. Carlos Alejandro Nome pela oportunidade de participar do experimento CASA NORDESTE 1.0 e enriquecer nossos conhecimentos profissionais.

\section{Referências}

ABNT (ASSOCIAÇÃO BRASILEIRA DE NORMAS TÉCNICAS). Instalações prediais de águas pluviais. NBR 10844 de dezembro de 1989.

AESA. (2018). Agência Executiva de Gestão das Águas do Estado da Paraíba. Disponível em: http://www.aesa.pb.gov.br/aesa-website/meteorologia-chuvas/. Acesso: 20 de agosto de 2018.

CAGEPA (COMPANHIA DE ÁGUA E ESGOTO DO ESTADO DA PARAíBA) $<$ http://agenciavirtual.cagepa.pb.gov.br/gsan/exibirConsultarEstruturaTarifariaPortalCagepaAction.do>. Acessado em 21 de agosto de 2018

CORMIER, S. NATHANIEL; PELLEGRINO, MESQUITA RENATO PAULO. Infra-estrutura verde: uma estratégia paisagística para a água urbana. São Paulo: Paisagem Ambiente - ensaios, 2008.

EDSON URBANO. <http://www.sempresustentavel.com.br/hidrica/minicisterna/custo-minicisternabasica.htm>. Acessado em 21 de agosto de 2018.

FURTADO, FÁTIMA; PRIORI, LUIZ; ALCÂNTARA, EDINÉA. Mudanças climáticas e resiliência de cidades. Recife: Pickimagem, 2015.

GHISI, E.; FERREIRA, D. Potential for potable water saving by using rainwater and greywater in a multistorey residential building in southern Brazil. Building and Environment, v.42, p.2512-2522, 2007.

INTITUTO AGRÔNOMO DE PERNAMBUCO. <http://www.ipa.br/resp28.php>. Acessado em 21 de agosto de 2018.

INSA (INSTITUTO NACIONAL DO SEMIÁRIDO) (2011). Recursos hídricos em regiões áridas e semiáridas. Campina Grande-PB. p 30.

MALQUI, F. A. dos S. M. Captação da água da chuva para utilização residencial. Santa Maria: UFSM. 2008. 85p. Trabalho de Conclusão de Curso

MEDICI, L. O.; Rocha HS ; CARVALHO, D. F. ; PIMENTEL, Carlos ; AZEVEDO, Ricardo Antunes de . Automatic controller to water plants. Scientia Agrícola (USP. Impresso), v. 67, p. 727-730, 2010.

PETERS, M. R. Potencialidade de uso de fontes alternativas de água para fins não potáveis e uma unidade residencial. Florianapolis: UFSC. 2006. 109p. Dissertação Mestrado

SILVA, G.. Aproveitamento de água de chuva em um prédio industrial e numa escola pública. Estudo de caso. Campinas: UNICMP. 2007. 87p. Tese Doutorado.

TOMAZ, P.(2003). Aproveitamento de água de chuva: para áreas urbanas e fins não potáveis. São Paulo: Navegar, 2003.

VALLE, J. A. B.; PINHEIRO, A.; FERRARI, A. Captação e avaliação da água de chuva para uso industrial. Revista de Estudos Ambientais, v.9, p.62-72, 2007. 